Surporting information

\title{
Graphene oxide-silver nancomposite: Novel agricultural antifungal agent against Fusarium graminearum for crop disease prevention
}

Juanni Chen ${ }^{1,2}$, Long Sun ${ }^{1}$, Yuan Cheng ${ }^{1}$, Zhicheng Lu ${ }^{1}$, Kang Shao ${ }^{1}$, Tingting Lit, Chao $\mathrm{Hu}^{1}$, Heyou $\mathrm{Han}^{1}$ *

${ }^{1}$ State Key Laboratory of Agricultural Microbiology, College of Plant Science and

Technology, College of Science, Huazhong Agricultural University, Wuhan, 430070,

P.R. China.

${ }^{2}$ Laboratory of Natural Product Pesticide, College of Plant protection, Southwest

University, Chongqing, 400715, P.R. China.

* Corresponding author. Tel: +86-27-87288505; Fax: +86-27-87288505

E-mail: hyhan@mail.hzau.edu.cn 

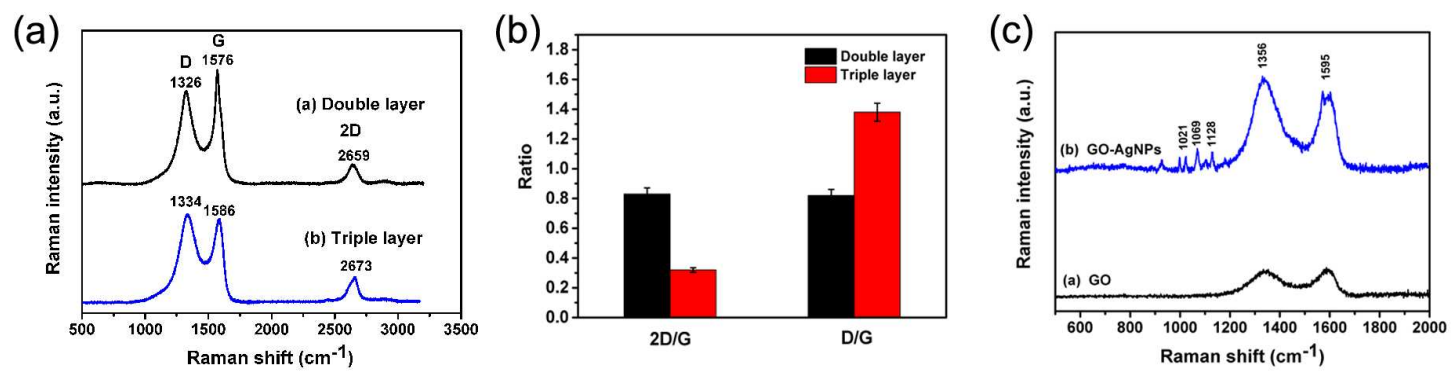

Figure S-1. Raman spectra of (a) Double and triple-layer graphene oxide and (b) their corresponding $\mathrm{D} / \mathrm{G}$ and 2D/G ratios; (c) Raman spectra of the as-prepared GO sheets and GO-AgNPs nanocomposite. 


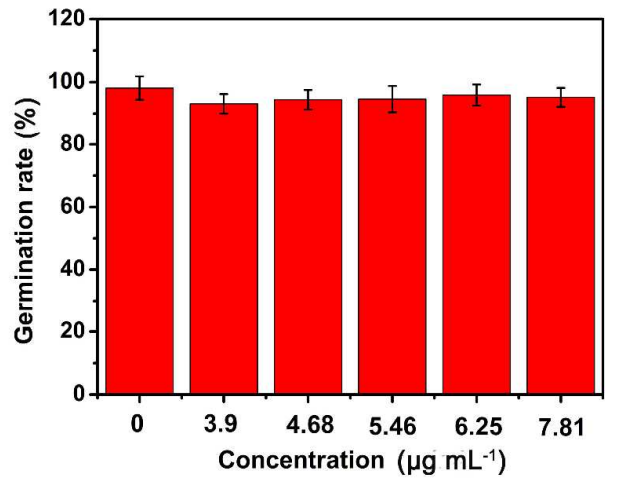

Figure S-2. The germination rate of spores treated with different concentration of PDDA at the concentration range from 3.9-7.81 $\mu \mathrm{g} \mathrm{mL}^{-1}$. 

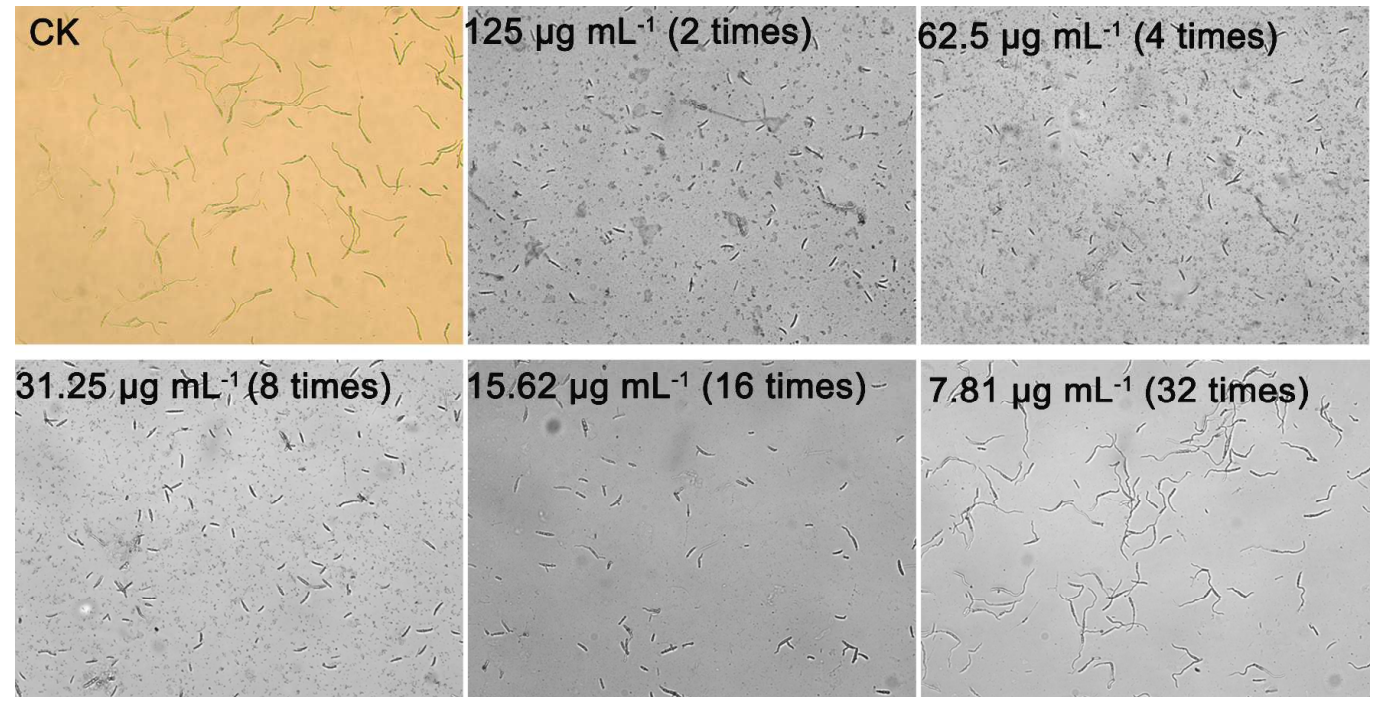

Figure S-3. Photomicrograph of macroconidia germination after treatment with GO-AgNPs nanocomposite, the concentration of which were diluted in a geometric progression from 2 to 32

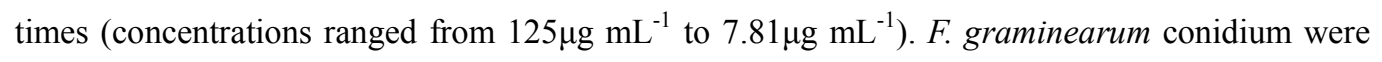
germinated on coverslips for $7 \mathrm{~h}$ at $28{ }^{\circ} \mathrm{C}$ 

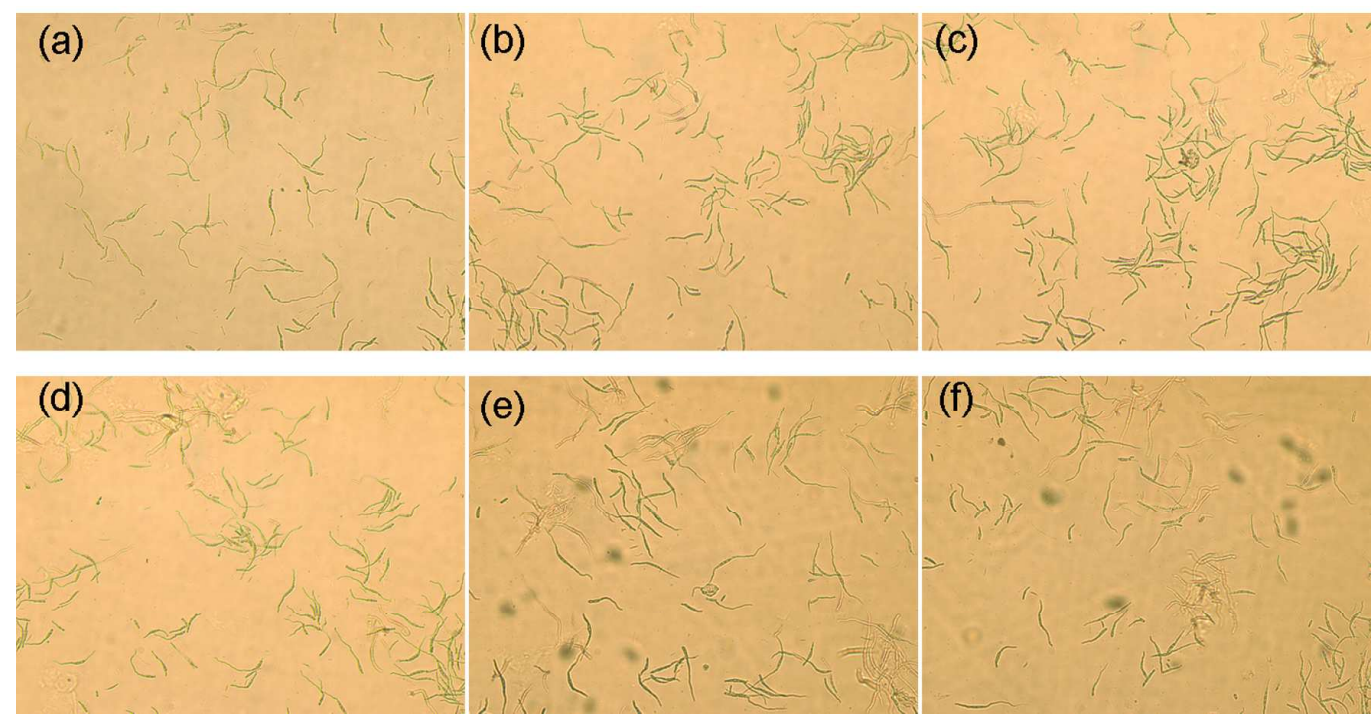

Figure S-4. Photomicrograph of macroconidia germination after treatment with (a) control water, (b) 3.9, (c) 4.68 , (d) 5.46 , (e) 6.25 , (f) $7.81 \mu \mathrm{g} \mathrm{mL} \mathrm{mL}^{-1}$ of GO sheets. F. graminearum conidium were germinated on coverslips for $7 \mathrm{~h}$ at $28{ }^{\circ} \mathrm{C}$. 

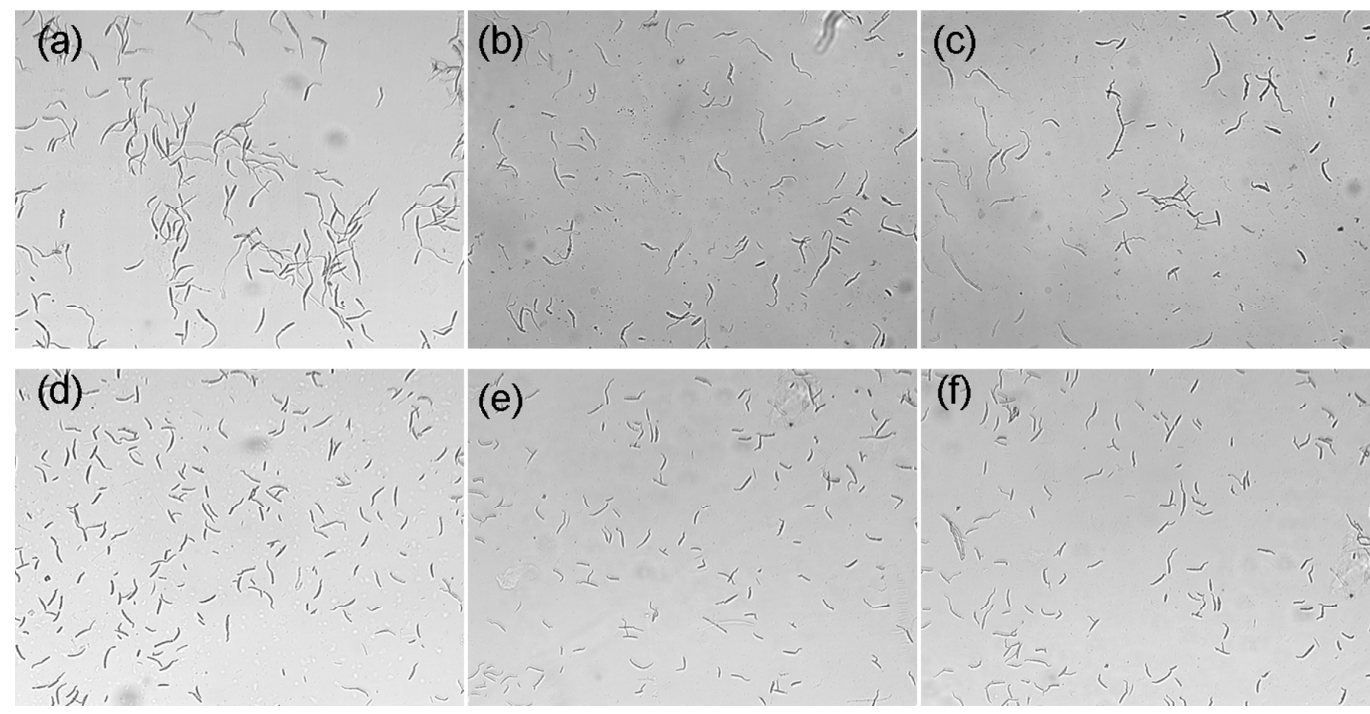

Figure S-5. Photomicrograph of macroconidia germination after treatment with (a) control water, (b) 3.9, (c) 4.68, (d) 5.46 , (e) 6.25 , (f) $7.81 \mu \mathrm{g} \mathrm{mL} \mathrm{m}^{-1}$ of AgNPs. F. graminearum conidium were germinated on coverslips for $7 \mathrm{~h}$ at $28{ }^{\circ} \mathrm{C}$ 


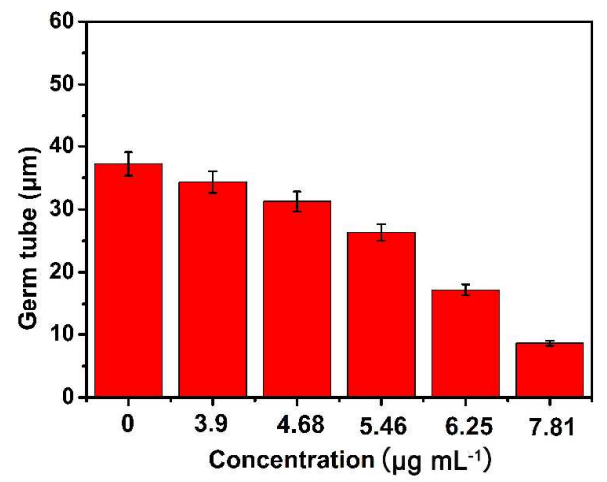

Figure S-6. The germ tube length of the $F$. graminearum conidium after treatment with control water and $3.9,4.68,5.46,6.25,7.81 \mu \mathrm{g} \mathrm{m}^{-1}$ of GO-AgNPs nanocomposite. 


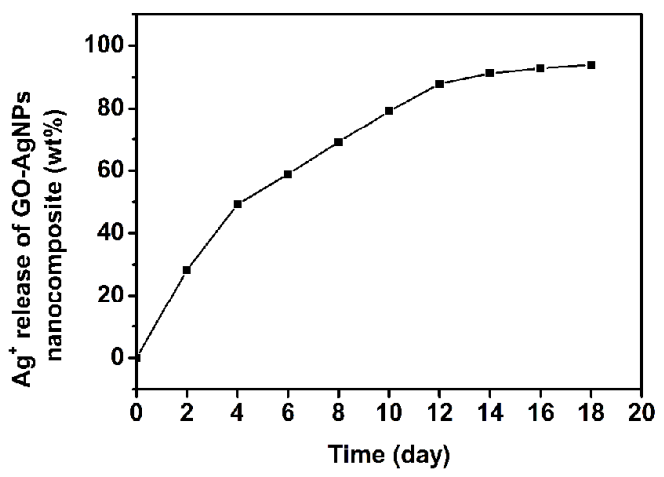

Fig. S-7. $\mathrm{Ag}^{+}$release of GO-AgNPs nanocomposite during 20 days. 


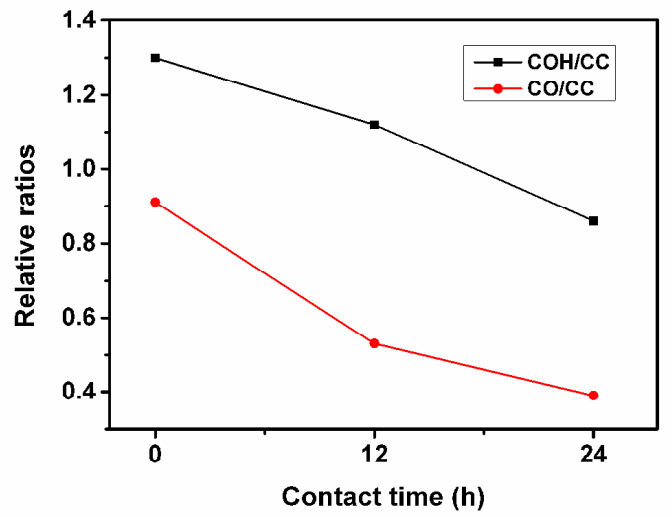

Fig. S-8 The peak area relative ratios of oxygen-containing functional groups to the $\mathrm{C}-\mathrm{C}$ bonds. 